\title{
Exogenous application of Salicylic Acid alleviates drought stress of rubber nursery plants in the Intermediate Zone of Sri Lanka
}

\section{S A Nakandala*, K D N Weerasinghe**, P Senevirathne*, S M M Iqbal*, W G D Lakmini*** and P M P S Vijithasiri***}

* Rubber Research Institute of Sri Lanka, Dartonfield, Agalawatta

** Department of Agric. Engineering, Faculty of Agriculture, University of Ruhuna, Mapalana, Kamburupitiya

*** Department of Crop Science, Faculty of Agriculture, University of Ruhuna, Mapalana, Kamburupitiya

\begin{abstract}
Drought is considered as one of the main environmental threats for plants that limits the growth and development. In the present study, salicylic acid (SA) was applied to mitigate the drought stress of rubber nursery plants. The study was conducted at Monaragala Sub Station, Rubber Research Institute of Sri Lanka during the dry months from May to September in 2015. The experimental design was Randomized Completed Block Design (RCBD) with five replicates. Treatments were droughtstressed (withholding of water), three concentrations of $S A(0.1 \mathrm{mM}, 0.3 \mathrm{mM}$ and $0.5 \mathrm{mM})$ and control(C) kept under regular irrigation. Drought was imposed by withholding water by weekly and lifesaving irrigation was done throughout the nursery period. Measurements were taken on morphological and physiological characters of seedling plants.

Plants which were treated with $S A$ as a soil drench at $0.1 \mathrm{mM}, 0.3$ and $0.5 \mathrm{mM}$ concentrations showed significant difference on drought stress plants when compare the stressed plant. Chlorophyll content and stomatal conductance $\left(g_{s}\right)$ in seedlings reduced drastically under moisture stressed conditions. Dry matter accumulation also decreased in drought stressed plants as compared to those treated with SA at 0.3 and $0.5 \mathrm{mM}$ concentrations. This indicates that the application of $S A$ had a positive effect on stomatal conductance and biomass accumulation under water stressed conditions.

In conclusion, the drought-stress decreased the growth of rubber nursery plants to a greater extent and exogenous application of $S A$ at $0.3 \mathrm{mM}$ and $0.5 \mathrm{mM}$ concentrations found to be effective in alleviating drought stress under sub optimal conditions in the Intermediate zone in Sri Lanka.
\end{abstract}

Key words: concentration, diameter, drought stress, rubber, Salicylic Acid 
S A Nakandala et al.

\section{Introduction}

Drought, the absence of rainfall for a period of time resulting in depletion of soil water, is considered as one of the main environmental constraints for plant growth and development. The permanent or temporary water deficit during drought severely reduces the plant growth and development than any other abiotic stresses (Anjum et al., 2011).

Drought induces oxidative stress in plants by generating reactive oxygen species (ROS) such as oxygen ions, free radicals, and peroxides (Farooq et al., 2009). ROS play an important role in cell signaling by activating defensive system in plants under abiotic stresses (Anjum et al., 2011).

This defense system consists of enzymatic and non-enzymatic antioxidant system, such as lowmolecular mass antioxidants (glutathione, ascorbate, carotenoids) and ROS scavenging enzymes (superoxide dismutase (SOD), peroxidase (POD), catalase (CAT), ascorbate peroxidase (APX). Combination of these systems acts to minimize the affections of oxidative stresses (Anjum et al., 2011).

Salicylic acid (SA) is known as a nonenzymatic and an anti-oxidative plant growth regulator present in plants which can play an important role in environmental stress by activating its inter defense mechanism and multiple stress tolerance (Senaratne et al., 2000). The SA regulates various physiological processes in plants such as seed germination, fruit yield, glycolysis, flowering and heat production in thermogenic plants (Klessing and Malamy, 1994; Senaratne et al., 2000), ion uptake and transport (Harper and Balke, 1981), photosynthesis rate, stomatal conductance and transpiration (Khan et al., 2003).

Exogenous application of SA has been shown to induce plant stress tolerance. For example, treatment of common bean (Phaseolus vulgaris L) and tomato (Solanum lycopersicum L.) plants with SA increased their drought tolerance (Senaratne et al., 2000). Exogenous application of SA also modulates activities of intracellular antioxidant enzymes SOD and POD and increases plant tolerance to environmental stresses.

Therefore, the present study was aimed at exploring the effect of salicylic acid in alleviating drought stress. This is the considered to be first report on the drought alleviation in rubber nursery plants by exogenous application of salicylic acid.

\section{Materials and method}

Site selection

A young budding rubber nursery at Monaragala Sub Station of Rubber Research Institute of Sri Lanka was selected for the experiment. The area belongs to the agro-ecological region; IL1c (Wijesuriya et al., 2010). The long dry spells prevailed in the Intermediate Zone from February to March and from May to September every year and therefore, soil moisture stress occurs due to lack of soil moisture, high 
evaporation, low relative humidity, high wind velocity and high temperatures. Hence the present study was conducted during the dry period from May to end of September in the year 2015.

\section{Experiment design and treatments}

The experimental design was Randomized Completed Block Design (RCBD) with five replicates. Treatments were drought-stressed plants with no application of salicylic acid and three treatments with different concentrations of salicylic acid applications (i.e.; $0.1 \mathrm{mM}, 0.3 \mathrm{mM}$ and $0.5 \mathrm{mM}$ ). Control plants were kept under regular irrigation. A seeding nursery was established in poly bags (7"x18") according to the above design in the field and irrigated initially until the soil in the poly bag reached field capacity. Salicylic acid at the concentrations of $0.1,0.3$ and $0.5 \mathrm{mM}$ was prepared and $100 \mathrm{ml}$ of the solution was applied to each one-month-old plant in two consecutive applications within a day as a soil drenching. Drought was imposed by withholding of irrigation for five months of study period. Life saving irrigation was done for the treatment plants once in five days throughout the study. The control plants were kept under daily irrigation up to field capacity. A repeated application of salicylic acid was done three months after the first application before bud grafting of the seedling plants. Recommended agro-management practices were done throughout the nursery period. Measurements on morphological and physiological characteristics of seedling plants were taken throughout the nursery period.

Plant stem diameter, plant height, leaf area and number of leaves were measured as morphological parameters. Plant diameter at $1 \mathrm{~cm}$ above the base of the seedling was measured by using digital venire caliper at two weeks intervals. The plant height was measured by using a measuring tape in every two weeks. Leaf area was determined once a month as on site measurement by using a leaf area meter (Delta T MK2). Fifteen plants in each treatment in three replicates were taken to measure all leaves of the plants. Total number of leaves of the above experimental plants was counted once in two weeks.

Plant physiological parameters such as stomatal conductance, chlorophyll content and leaf temperature were measured every two weeks throughout the study period. Stomatal conductance and leaf temperature were measured by using a portable porometer (Delta $\mathrm{T}$ AP4). Three plants from each replicate of each treatment were measured mid day and completed within an hour under same light condition. Measurements were taken in top mature leaf and right leaflet of each treatment plant once in two weeks.

Leaf chlorophyll content was measured by non-destructive method, using a chlorophyll meter (SPAD 502DL Plus). The meter gives chlorophyll content as an index value (SPAD value) that is proportional to the amount of 
S A Nakandala et al.

chlorophyll content of leaves. Average measurement was taken on one of top mature leaf.

Plants were uprooted after four months and measured tap root length, secondary root lengths and total plant dry matter content. Shoot:root ratio was calculated. Destructive samples were taken to analyze dry matter content and shoot: root. Samples were oven dried at $85^{\circ} \mathrm{C}$ for constant weight.

Statistical analysis was done by analysis of variance followed by a mean separation procedure, Duncan's Multiple Range test (DMRT), at a probability level of 0.05 . SAS statistical software package - version 9.0 (SAS Inc., USA) were used to analyze data.

\section{Results}

Morphological responses of plants

Table 1 shows the effect of different salicylic acid treatment on stem diameter of rubber seedlings plants up to eight weeks after application. A significant variation in diameter increment was shown under different
SA concentrations from 4th weeks of application. Values in the Table 1 shows that the salicylic acid concentrations 0.1 to $0.5 \mathrm{mM}$ positively effect on stem diameter increment on plants after four weeks of application and after 8 weeks, effect was persist in 0.3 and $0.5 \mathrm{mM}$ concentrations. A lower concentration of SA that is $0.1 \mathrm{mM}$ showed a lower rate of diameter increment in $8^{\text {th }}$ weeks when compared with other two concentrations.

The effect of salicylic acid concentrations on plant height, leaf area, number of leaves and root characters are shown in Table 2. Restricted plant height was shown when the plants were drought stressed and there were no significant difference in plant height among treatment in relation to SA concentrations. Leaf area values of treatment plants showed that the plants which were treated with salicylic acid at $0.5 \mathrm{mM}$ concentration remained a significant higher value of leaf area when compare of 0.1 and $0.3 \mathrm{mM}$ concentrations.

Table 1. Effect of exogenous application of salicylic acid concentrations on diameter of rubber seedlings in millimeters $(C$ - normal irrigation, $D R$ - drought-stressed (withholding of water), $D R+0.1 m M, D R+0.3 m M$ and $D R+0.5 m M-$ drought stressed + three concentrations of $S A$

\begin{tabular}{llllll}
\hline \multirow{2}{*}{ Treatment } & \multicolumn{5}{c}{ Weeks after application of salicylic acid } \\
\cline { 2 - 6 } & Initial & $\mathbf{2}$ & $\mathbf{4}$ & $\mathbf{6}$ & $\mathbf{8}$ \\
\hline $\mathrm{C}$ & $3.70 \pm 0.04$ & $5.15 \pm 0.09^{\mathrm{a}}$ & $5.64 \pm 0.07^{\mathrm{a}}$ & $6.75 \pm 0.10^{\mathrm{a}}$ & $7.84 \pm 0.11^{\mathrm{a}}$ \\
$\mathrm{DR}$ & $3.77 \pm 0.04$ & $5.08 \pm 0.06^{\mathrm{a}}$ & $5.44 \pm 0.05^{\mathrm{b}}$ & $6.32 \pm 0.07^{\mathrm{b}}$ & $6.99 \pm 0.06^{\mathrm{b}}$ \\
$\mathrm{DR}+0.1 \mathrm{mM}$ & $3.84 \pm 0.04$ & $5.17 \pm 0.05^{\mathrm{a}}$ & $5.66 \pm 0.05^{\mathrm{a}}$ & $6.47 \pm 0.05^{\mathrm{b}}$ & $7.02 \pm 0.08^{\mathrm{b}}$ \\
$\mathrm{DR}+0.3 \mathrm{mM}$ & $3.78 \pm 0.03$ & $5.12 \pm 0.07^{\mathrm{a}}$ & $5.54 \pm 0.07^{\mathrm{ab}}$ & $6.33 \pm 0.10^{\mathrm{b}}$ & $7.50 \pm 0.10^{\mathrm{a}}$ \\
$\mathrm{DR}+0.5 \mathrm{mM}$ & $3.66 \pm 0.04$ & $5.08 \pm 0.08^{\mathrm{a}}$ & $5.48 \pm 0.07^{\mathrm{ab}}$ & $6.33 \pm 0.07^{\mathrm{b}}$ & $7.58 \pm 0.03^{\mathrm{a}}$ \\
\hline \multicolumn{5}{c}{ (Means with the same letter in a column are not significantly different) } \\
\hline \multicolumn{6}{c}{}
\end{tabular}


SA alleviate drought stress of rubber nursery plants

Table 2. Effect of salicylic acid application on plant height, leaf area and root growth of rubber seedlings after eight weeks of $S A$ application (C - normal irrigation, DR drought-stressed (withholding water), $D R+0.1 m M, D R+0.3 m M$ and $D R+0.5 m M$ - drought + three concentrations of $S A$ )

\begin{tabular}{llllll}
\hline Treatment & plant height & leaf area $\left(\mathbf{c m}^{2}\right)$ & $\begin{array}{l}\text { No. of } \\
\text { Leaves }\end{array}$ & & \multicolumn{2}{c}{ Root length $(\mathbf{c m})$} \\
\cline { 4 - 6 } & & & & $\begin{array}{l}\text { Tap root } \\
(\mathbf{c m})\end{array}$ & $\begin{array}{l}\text { Secondary } \\
\text { roots }(\mathbf{c m})\end{array}$ \\
\hline $\mathrm{C}$ & $89.05 \pm 1.51^{\mathrm{a}}$ & $1098.57 \pm 40.20^{\mathrm{a}}$ & $14 \pm 0.44^{\mathrm{a}}$ & $43.0 \pm 2.31^{\mathrm{b}}$ & $427.6 \pm 15.88^{\mathrm{bc}}$ \\
$\mathrm{DR}$ & $77.24 \pm 1.40^{\mathrm{b}}$ & $830.04 \pm 54.16^{\mathrm{b}}$ & $08 \pm 0.45^{\mathrm{b}}$ & $52.7 \pm 5.36^{\mathrm{a}}$ & $619.2 \pm 19.78^{\mathrm{a}}$ \\
$\mathrm{DR}+0.1 \mathrm{mM}$ & $79.59 \pm 1.32^{\mathrm{ab}}$ & $933.82 \pm 63.01^{\mathrm{ab}}$ & $10 \pm 0.57^{\mathrm{a}}$ & $47.0 \pm 1.35^{\mathrm{ab}}$ & $441.6 \pm 31.84^{\mathrm{bc}}$ \\
$\mathrm{DR}+0.3 \mathrm{mM}$ & $77.85 \pm 1.37^{\mathrm{ab}}$ & $952.66 \pm 70.82^{\mathrm{ab}}$ & $12 \pm 0.45^{\mathrm{a}}$ & $48.5 \pm 4.11^{\mathrm{ab}}$ & $404.3 \pm 50.33^{\mathrm{c}}$ \\
$\mathrm{DR}+0.5 \mathrm{mM}$ & $79.66 \pm 1.34^{\mathrm{ab}}$ & $1052.36 \pm 62.72^{\mathrm{a}}$ & $11 \pm 0.37^{\mathrm{a}}$ & $49.2 \pm 5.14^{\mathrm{ab}}$ & $527.7 \pm 42.86^{\mathrm{b}}$ \\
\hline
\end{tabular}

(Means with the same letter in a column are not significantly different)

According to the results, the plants under water stress condition without SA treatment recorded the lowest mean values $(\mathrm{p}<0.05)$ of total number of leaves and it was significantly lower compared to all other treatments. Control plants which were irrigated regularly recorded the highest mean value for total number of leaves per plant. When the moisture stressed plants were treated with SA, number of leaves remained similar to control.

Drought-stressed plants with or without SA application recorded a significantly $(p \leq 0.05)$ higher mean length of tap root compared to non-stressed control treatment. The plants treated with 0.5 $\mathrm{mM}$ concentration of SA increase the secondary root lengths when compare to $0.1 \mathrm{mM}$ and $0.3 \mathrm{mM}$ concentrations.

\section{Physiological responses}

Leaf chlorophyll content is a major component of the photosynthetic system. Figure 1 shows the variation of chlorophyll content of plants after 8 weeks of treatment applied. There was a significantly lower $(\mathrm{p} \leq 0.05)$ chlorophyll content in drought-stressed plants without SA application. Drought plants which were treated with $0.5 \mathrm{mM}$ concentration of SA (DR + 0.5SA) showed a higher chlorophyll content similar to control plants and less in 0.1 and $0.3 \mathrm{mM}$ concentrations (Fig. 1).

Fig. 2 indicates the variation of stomatal conductance $\left(g_{s}\right)$ and leaf temperature of treatment plants after $8^{\text {th }}$ weeks of SA application. SA treated plants maintained a higher $g_{s}$ value even at high temperatures indicating that the application of SA had positive effects on $g_{s}$ (Fig. 2). 


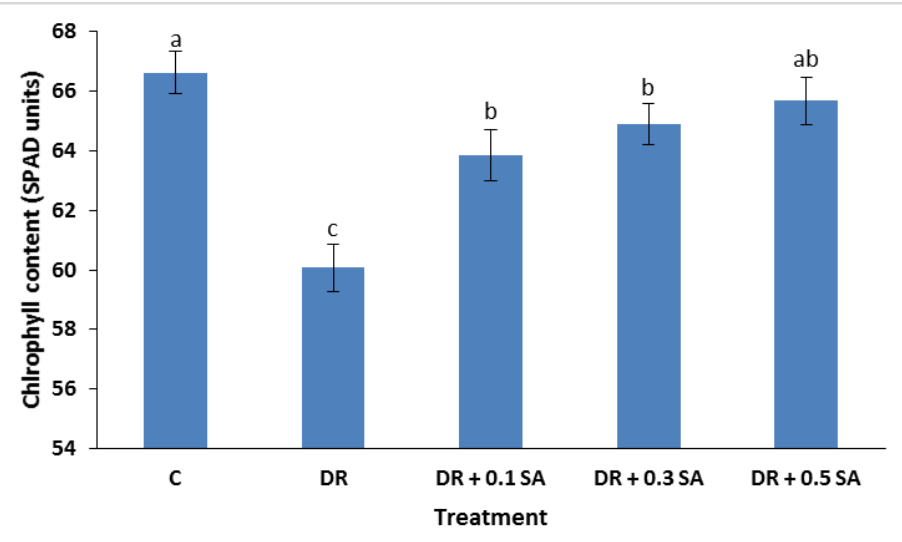

Fig. 1. Chlorophyll content of rubber seedlings at eight weeks after application (C - normal irrigation, DR - drought-stressed (withholding water), DR + 0.1 $\mathrm{mM}, \mathrm{DR}+0.3 \mathrm{mM}$ and $\mathrm{DR}+0.5 \mathrm{mM}-$ drought + three concentrations of SA). (Means with the same letter in a column are not significantly different)

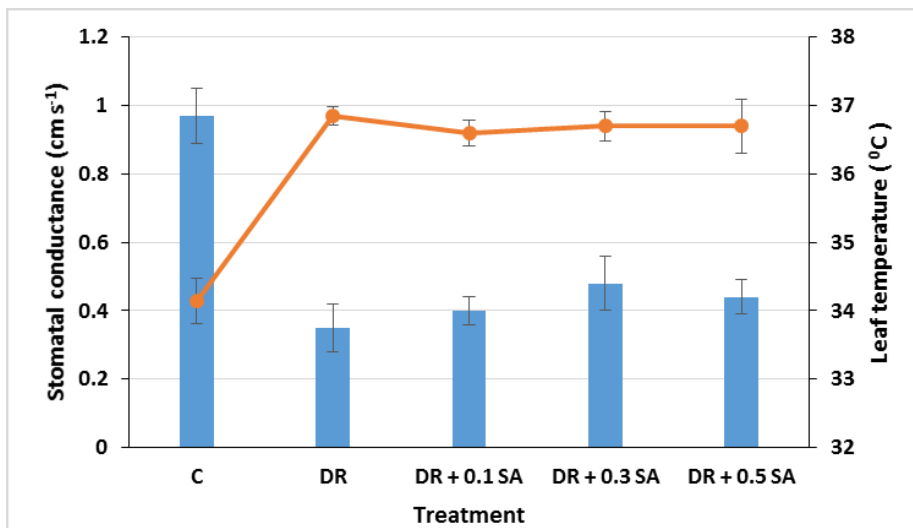

Fig. 2. Stomatal conductance and leaf temperature of plants after eight weeks of application of salicylic acid (C - normal irrigation, DR - drought-stressed (withholding water), DR + $0.1 \mathrm{mM}, \mathrm{DR}+0.3 \mathrm{mM}$ and $\mathrm{DR}+0.5 \mathrm{mM}-$ drought + three concentrations of SA).

Table 3 shows the variation of dry matter content and shoot: root ratio of plants treated with different SA concentrations under drought stress condition. According to the values of the different parts of the treatment plants, there was a positive trend of increased the total dry weight in SA treated plants and drought stress plants due the dry matter increment on drought response. 
SA alleviate drought stress of rubber nursery plants

Table 3. Effect of salicylic acid application on dry matter production under drought stress

\begin{tabular}{llllll}
\hline Treatment & \multicolumn{3}{c}{ Dry weight (g/plant) } & $\begin{array}{l}\text { Total dry weight } \\
\text { (g/plant) }\end{array}$ & $\begin{array}{l}\text { Shoot: root } \\
\text { ratio }\end{array}$ \\
\cline { 2 - 5 } & Stem & leaves & roots & 15.00 & $2.75^{\mathrm{a}}$ \\
$\mathrm{C}$ & $6.50 \pm 1.58$ & $4.50 \pm 0.32$ & $4.00 \pm 0.60$ & $1.97^{\mathrm{b}}$ \\
$\mathrm{DR}$ & $5.66 \pm 0.25$ & $3.36 \pm 0.52$ & $4.58 \pm 0.25$ & 13.60 & $2.13^{\mathrm{ab}}$ \\
$\mathrm{DR}+0.1 \mathrm{SA}$ & $6.33 \pm 0.25$ & $3.33 \pm 0.52$ & $4.53 \pm 0.25$ & 14.19 & $2.22^{\mathrm{ab}}$ \\
$\mathrm{DR}+0.3 \mathrm{SA}$ & $6.33 \pm 1.53$ & $4.00 \pm 0.77$ & $4.66 \pm 0.25$ & 14.99 & $2.04^{\mathrm{ab}}$ \\
$\mathrm{DR}+0.5 \mathrm{SA}$ & $7.5 \pm 1.06$ & $4.25 \pm 0.43$ & $5.75 \pm 0.43$ & 17.50 & \\
\hline
\end{tabular}

Table 3 shows that the root development under drought condition less affected when compared to shoot growth. Thus, a decrease in shoot:root ratio is a common observation under drought stress, which results either from an increase in root growth or from a decrease in shoot growth.

\section{Discussion}

Drought stress poses adverse effects on rubber seedlings including morphological and plant physiological changes. Drought leads to substantial impairment of growth-related traits in terms of plant height, leaf area, number of leaves per plant as found in this experiment. Total leaf area of stressed plants reduces due to loss of leaf turgor and high temperature. The present study showed that water stress suppressed the expansion of leaves and resulted in reduced leaf area, causing reduced availability of assimilates for stem growth. Similar results were reported by Anosheh et al. (2012) indicating the negative effect of drought on plant growth. However, the present study showed that the application of salicylic acid in different concentrations have a positive effect on morphological traits of rubber seedlings (Table 1 and 2).

Extensive root systems are developed by plants in response to the drought stress. A greater percentage of fine roots, capable of penetrating smaller soil pores, presumably optimises the exploratory capabilities of the root system as a whole and may have an important role in the survival of plants under drought stress. Root signaling during drought stress supports plant growth during the early stages of crop growth and extract water from shallow soil layers that is otherwise easily lost by evaporation (Anjum et al., 2011). The similar rooting pattern was shown in rubber seedlings under stress conditions which help to strive nursery plants until stress conditions recovered (Table 2).

Drought stress creates numerous physiological effects on plants, including less chlorophyll content, stomatal closer and increase in leaf temperature. However, these adverse effects could be partially alleviated by applying SA. In the present study, exogenous application of SA resulted in increased of chlorophyll content when 
S A Nakandala et al.

compared with the water stressed plants without SA application. Singh, (2003) reported the direct effect of chlorophyll content of plants, photosynthetic rate, and net $\mathrm{CO}_{2}$ assimilation. Chlorophyll content as photosynthetic pigments is important to plant mainly for harvesting light and production of organic compounds. Drought stress causes large decline in both chlorophyll content and low concentrations of chlorophyll pigments can directly limit photosynthetic potential and hence, primary production (Anjum et al., 2011). The results obtained from the present study clearly indicated that the exogenous SA application significantly improved the level of chlorophyll content under 0.3 to $0.5 \mathrm{mM} \mathrm{SA}$ concentrations (Fig. 1).

Stomatal regulation is another key process involving in the photosynthesis process. Results obtained for stomatal regulation under in each concentration are in conformity with the work reported by Habbi, (2012). Stomatal conductance was reduced strongly under water stress conditions but increased with SA application. Results showed that application of salicylic acid indicates a positive effect on stomatal conductance under higher leaf temperatures (Fig. 2).

The water deficit also increased leaf temperature of stressed plants in all treatments. Anosheh et al. (2012) reported that soil water content had a direct effect on leaf temperature and the effect of water deficit was more pronounced. However, high leaf temperature induces defense mechanisms and gene expression to modulate plants responses (Habbi, 2012). Salicylic acid-mediated improved plant tolerance to heat stress has also been reported (Larkindale et al., 2005). Therefore, the present study indicated that SA plays an important role in inducing heat stress tolerance by increasing the activity of the antioxidant system of plants.

The overall study highlights the drought stress decreased the plant growth severely and application of salicylic acid in the range of 0.3 to $0.5 \mathrm{mM}$ as soil drench enhanced plant growth by adjusting various morphological and physiological characters of stressed plants which are badly affected by drought stress. Therefore, an exogenous application of salicylic acid is found to be a promising and feasible option in alleviating negative effects of rubber nursery plants under drought conditions at the Intermediate zone in Sri Lanka.

\section{Acknowledgement}

The authors are thankful to Dr W M G Seneviratne, Director of the Rubber Research Institute of Sri Lanka for granting permission to carry out this study at the Sub-station Monaragala. Late Dr Tissa Senarathna, is duly acknowledged for the encouragement of the second author to share his research findings and ideas in stress physiology under Sri Lankan conditions. 


\section{References}

Anjum, S A, Xie, X, Wang, L, Saleem, M F, Man, C and Lei, W (2011). Morphological, physiological and biochemical responses of plants to drought stress. African Journal of Agricultural Research 6 (9), 2026-32.

Anosheh, H P, Emam, Y, Ashraf, M and Foolad, M R (2012). Exogenous application of salicylic acid and chlormequat chloride alleviates negative effect of drought stress in wheat. Advance Studies in Biology 4, No.11, 501-520.

Farooq, M, Whid, A, Koboyashi, N, Fujita, D and Basra, S M A (2009). Plant drought stress: effects mechanisms and management. Agronomy for Sustainable Development, Springer Verlag/EDP Sciences/INRA, 29 (1), 185-212.

Habbi, G (2012). Exogenous salicylic acid alleviates oxidative damages of barley plants under drought stress. Acta biologica Szegediensis 56, 57-63.

Harper, J R and Balke, N E (1981). Characterization of the inhibition of $\mathrm{K}$ absorption in oats roots by salicylic acid. Plant Physiology 68, 1349-53.

Khan, W, Prithviraj, B and Smith, D L (2003). Photosynthetic responses of corn and soybean to foliar application of salicylates. Journal of Plant Physiology 160, 485-92.
Klessig, D F and Malamy, J (1994). The salicylic acid signal in plants. Plant Molecular Biology 26, 1439-58.

Lakindale, J, Hall, J D, Knight, M R and Verling, E (2005). Heat stress phenotypes of Arabidopsis mutants implicate multiple signaling pathways in the acquisition of thermotolerance. Plant physiology 138, 882-97.

Senaratna, T, Touchell, D, Bunn, $\mathrm{T}$ and Dixon, K (2000). Acetyle salicylic acid (Aspirin) and salicylic acid induce multiple stress tolerance in bean and tomato plants. Plant Growth Regulator 30, 157-61.

Singh, B and Usha, K (2003). Salicylic acidinduced physiological and biochemical changes in wheat plants under water stress. Plant Growth Regulators 39, 137 141.

Wijesuriya, W, Herath, K and Karunarathne (2010). Use of rainfall pattern for efficient operation of agronomic practices in rubber plantations: The case of Moneragala District. Bulletin of the Rubber Research Institute of Sri Lanka 51, 70-80.

Address for correspondence: Mrs S A Nakandala, Research Officer, Plant Science Dept., Rubber Research Institute of Sri Lanka, Dartonfield, Agalawatta, Sri Lanka. e-mail:sashika_75@yahoo.com 